Un horizonte de progreso. Murales argentinos en las exposiciones universales

Cecilia Belej

Boletín de Arte (N.․ 20), e024, septiembre 2020, ISSN 2314-2502

https://doi.org/10.24215/23142502e024

http://papelcosido.fba.un/p.edu.ar/ojs/index.php/boa

Facultad de Artes. Universidad Nacional de La Plata

La Plata. Buenos Aires. Argentina

\title{
UN HORIZONTE DE PROGRESO
}

\section{MURALES ARGENTINOS EN LAS EXPOSICIONES UNIVERSALES'}

\section{A HORIZON OF PROGRESS}

\author{
ARGENTINE MURALS IN THE WORLD FAIRS
}

\author{
Cecilia Belej / cbelej@gmail.com \\ Consejo Nacional de Investigaciones Científicas y Técnicas (CONICET). Instituto de Investigación \\ en Arte y Cultura Dr. Norberto Griffa. Universidad Nacional de Tres de Febrero / Universidad de \\ Buenos Aires. Argentina
}

Recibido: $15 / 3 / 2020$

Aceptado: 23/7/2020

\begin{abstract}
RESUMEN
Las exposiciones universales funcionaron como un espacio de conversación y de competencia entre las naciones. Allí se exhibían los logros industriales, las invenciones y las curiosidades de cada país. Los países latinoamericanos se esforzaban por presentar una imagen próspera por medio de los elementos exhibidos, la arquitectura y la decoración interior de su pabellón, que se hacía con pinturas murales efímeras que solo duraban el tiempo de la exposición. El objetivo de este trabajo es analizar los murales que se realizaron para el Pabellón Argentino de una serie de exposiciones universales para comprender su narrativa visual en torno a qué imagen de la Argentina se buscaba proyectar. Nos centraremos en las exposiciones que se desarrollaron en el periodo de entreguerras, fundamentalmente en la Exposición de Sevilla, de 1929; la de París, de 1937; y la de Nueva York, de 1939.
\end{abstract}

\section{PALABRAS CLAVE}

Exposiciones internacionales; pintura mural; Pabellón Nacional; Argentina

\section{ABSTRACT}

World fairs have been a place to communicate and, at the same time, compete among the nations. In the pavilions of every country, their features were intended to be reflected through architecture, interior decoration and the exhibited elements. Latin-American countries made huge efforts to present a prosperous image. Each pavilion was decorated with ephemeral wall paintings, which only lasted the time of the exhibition and that we can study through photographs and other documents. The aim of this paper is to analyze the murals that were made for the Argentine pavilions of a series of world fairs. We will focus mainly on those exhibitions that took place in the interwar period, especially the International Exhibitions in Seville (1929), Paris (1937) and New York (1939) in order to understand what the visual narrative projected with these images of the ideal Argentina was.

\section{KEYWORDS}

International Exhibitions; mural painting; National Pavilion; Argentina

1 Una versión preliminar de este texto se presentó en las XVI Jornadas Interescuelas / Departamentos de Historia, Facultad de Humanidades de la Universidad Nacional de Mar del Plata, 9, 10 y 11 de agosto de 2017. 
Las exposiciones universales, en la segunda mitad del siglo XIX, conformaron espacios para la comunicación de los logros imperialistas de las naciones, un lugar en el cual exhibir los productos de las culturas dominadas y una ocasión para la presentación de materias primas, animales e, incluso, personas consideradas exóticas. La primera de estas se realizó en Londres en 1851 y atrajo un gran público. En las ferias mundiales, a la manera de una ciudad, había zonas de entretenimiento, zonas para exhibir máquinas en funcionamiento, lugares para comer, entre otras atracciones. La disposición de los pabellones de cada país no era casual: se disponían en avenidas y calles de acuerdo a su importancia relativa. Los países latinoamericanos tenían un lugar secundario y cada uno se esmeraba por brillar ante la opulencia de los países centrales. A su vez, la estructura de los pabellones se organizaba de acuerdo a varios ejes, entre ellos la economía, los desarrollos urbanísticos y la cultura. A lo largo del siglo xx continuaron estas exposiciones, cada vez más elaboradas, y comenzaron a celebrarse en América.

El Estado argentino participó en varias con un pabellón propio donde presentaba, como si se tratara de un escaparate, una visión de la Argentina como una nación civilizada y productiva ante la mirada extranjera. En estas exposiciones no solo se presentaban productos de la agricultura y de la ganadería, sino que, también, se mostraban las maquetas de los nuevos edificios públicos. Así, se remarcaba que era motivo de orgullo el tipo de obra pública y de infraestructura edilicia que modernizaba las ciudades argentinas y, en especial, su capital, que hacia la década del treinta se encontraba en febril construcción de edificios al estilo de los rascacielos. ${ }^{2}$

En los pabellones, se completaba la decoración con murales que condensaban, de forma sintética, el sentido de lo que se quería mostrar. La idea central que guía este trabajo es que estos paneles murales que decoraron los pabellones nacionales permitieron expresar una noción de la Argentina, concebida por el Estado, para un público extranjero. Esta estuvo tensionada entre exponer una imagen telúrica y una ligada a la producción agroganadera e industrial. A su vez, la figuración resultó crucial para lograr comunicar, y poder ser comprendida, una narrativa visual que proyectara un mensaje claro con relación a qué se consideraba "lo argentino". Artistas como Antonio Berni, Lino Enea Spilimbergo, Adolfo Montero, Alfredo Guido, Ernesto Scotti y Gastón Jarry, entre otros, fueron los artífices de estos murales efímeros que solamente eran exhibidos durante el tiempo de las exposiciones y para un público extranjero.

El objetivo de este trabajo es, entonces, estudiar de qué manera se representó visualmente a través de los murales en los pabellones argentinos "lo argentino". Para ello, se tomarán las exposiciones internacionales en las que la Argentina participó durante el período de entreguerras. Nos centraremos en la "Exposición Iberoamericana de Sevilla", en 1927; la "Exposición Internacional de París», de 1937, y la "Exposición Mundial de Nueva York», de 1939. ${ }^{3}$ El período de entreguerras posee características propias que permitieron condensar una serie de sentidos en torno a la nacionalidad y las propuestas por cristalizar una representación de la misma. Entre el fin de la Primera Guerra Mundial y el comienzo de la Segunda Guerra Mundial, se observa una polarización de las ideas, tanto de izquierda como de derecha; en el plano económico se pasó de una recuperación a una estrepitosa crisis en 1930 que puso fin a los sueños de progreso. En este tiempo de paz, enmarcado por dos guerras, la

2 El desarrollo arquitectónico de las exposiciones ha recibido bastante atención por parte de los arquitectos, dado que la construcción de los pabellones ad hoc permite observar un muestreo de las tendencias arquitectónicas de cada época. Ramón Gutiérrez (2014) señala que el aspecto arquitectónico de los pabellones resultaba fundamental por ser el contenedor de lo que se exhibiría.

3 En el año 1922 se realizó en Río de Janeiro la «Exposición Internacional del Centenario de la Independencia de Brasil». La Argentina participó con un pabellón construido por el Arquitecto Alejandro Christophersen. Sabemos que contó con relieves de Troiano Troiani que representaban "la ganadería, la agricultura, las industrias y los frigoríficos" (Christophersen, 1923, p. 65). Lamentablemente, no contamos con fotografías de su interior. 
Argentina participó en las exposiciones internacionales, en un clima festivo, un momento para compartir los nuevos conocimientos e invenciones que encontrarán un límite a la camaradería con el estallido de la Segunda Guerra. Asimismo, queremos señalar que durante el período la pintura mural fue utilizada para comunicar narrativas visuales no solamente por la Argentina, sino, también, por otros países.

El trabajo se inscribe en los estudios de historia cultural y en él se combina el análisis de imágenes, en particular murales, con los aportes de los estudios visuales - a partir de los trabajos de Michael Ann Holly y Keith Moxey (2002) - que buscan examinar el papel de la imagen en la vida de la cultura, considerándola no solo dentro de su contexto de producción, sino, también, dentro del horizonte cultural de sus recepciones. Se considera así la posibilidad de acceder a un análisis de las imágenes y su interpretación vinculado con la noción de representación. Las fuentes que se utilizaron son fotografías, periódicos y catálogos que permiten reponer la visualidad de los murales, en su mayoría perdidos.

\section{LAS EXPOSICIONES INTERNACIONALES}

Lisa Schrenk (1999) ha señalado que hasta la década de 1930 se intentaba expresar a través de las arquitecturas de los pabellones la potencia de los imperios europeos por medio de una tradición histórica que recreaba aldeas medievales. Pero, como sostiene la autora, desde principios de los treinta se buscó construir una noción de modernidad, progreso y desarrollo industrial. Así, mientras que durante el período de expansión del imperialismo, entre el último tercio del siglo XIX y hasta el estallido de la Primera Guerra Mundial, las exposiciones internacionales se convirtieron en el lugar donde se desplegaban los logros imperiales, en el período de entreguerras la competencia entre las potencias es más velada: la exposición que cierra el período estudiado es La Feria Mundial: El mundo del mañana, en 1939 en Nueva York, que buscó proyectar hacia el futuro el estado de la cultura norteamericana. Por ejemplo, se colocó una cápsula de tiempo con productos de la civilización para ser abierta en cinco mil años. Esta contenía discos, libros, un paquete de cigarrillos Camel y un muñeco del ratón Mickey Mouse, entre otros artefactos que se consideraron relevantes de la cultura occidental, situada en Norteamérica. También se exhibió Futurama, una maqueta de una ciudad con autopista de gran velocidad, granjas organizadas científicamente y otras escenas que hablaban más del momento de producción que del futuro. Paradójicamente, la exposición fue la antesala de la Segunda Guerra Mundial, cuando aquel mundo de progreso se vio interrumpido por el conflicto bélico.

Las ferias universales duraban aproximadamente seis meses, tiempo en el cual eran visitadas por locales y por extranjeros. Había shows de baile, danza acuática, payasos y, sobre todo, los últimos adelantos técnicos. Como espectáculo de masas resultan iluminadoras para la comprensión de cómo se promovieron diversas formas de consumo cultural. A pesar de su carácter efímero, estas construcciones tuvieron gran impacto en la arquitectura del siglo XX en estilos como el art nouveau y el liberty, entre otros. Para Ramón Gutiérrez (2014), justamente, estos espacios permitían una exploración de nuevos estilos.

\section{Postales de la Argentina telúRICA}

En 1929 se realizó la «Exposición Iberoamericana de Sevilla», en la que fue convocado Alfredo Guido para realizar las pinturas del Pabellón argentino. De todos los paneles pintados para las exposiciones durante el período estudiado, el mural de Guido es el único que se conservó y puede contemplarse en una escuela de la ciudad de Rosario, donado por el artista a poco de terminada la exposición. ${ }^{4}$ Del intercambio epistolar que mantuvo con Enrique Larreta,

4 El mural fue adaptado en 1936 para revestir las paredes de la biblioteca de la Escuela Normal Superior N.$^{\circ} 2$

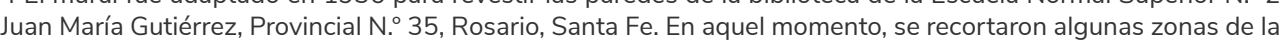
tela para colocar las bibliotecas. Más tarde, estas fueron retiradas y los espacios vacíos se pintaron de rojo (color predominante en la pintura). Agradezco las imágenes del mural a los profesores Sebastián Llansa y Carolina Helman. 
presidente de la delegación argentina en la exposición, podemos observar algunas de las ideas en juego. El pabellón, construido en estilo neocolonial por Martín Noel, ${ }^{5}$ se trataba de un manifiesto arquitectónico en el cual plasmó sus ideas sobre el retorno a las raíces hispanas tamizadas por la cultura americana (Gutman, 1995). Tanto Noel como Alfredo y su hermano, el arquitecto Ángel Guido, participaron del ideario promovido por Ricardo Rojas de un nacionalismo cultural que sintetizara las raíces indígenas con la tradición española. La pintura mural de Guido formó parte de este programa que desarrolló en esta obra y en la década siguiente (Belej, 2011, 2014).

En una carta que Guido le escribió a Larreta $^{6}$ el 25 de enero de 1927 puede palparse en toda su complejidad el conflicto que suponía representar en imágenes la identidad argentina: ¿debía ser indígena, criolla o europea? Para Guido se debía representar el folclore como núcleo de lo nacional, incluyendo también los trabajos en el campo y las actividades productivas. Con ironía, Guido (1927) le comenta a Larreta que en La Prensa había una crítica a los propósitos del comité del pabellón sobre los temas a decorar:

¡Ha sido una crítica escrita por un simple, porque cómo puede ocurrírsele que se decore a base de indios con plumas o cacharros calchaquíes el Pabellón Argentino! El espíritu de lo propuesto por ese Comité, o sea exigía que las características de la decoración sean puramente nuestras, no significa la eliminación de los trabajos del puerto y las faenas del trigo. Precisamente esas actividades tienen en esta tierra, para el que las mira con observación, un sello completamente nuestro y son el complemento de fuerza, a nuestras canciones, danzas y música.

La elección de Guido de cómo mostrar lo nacional fue a través del paisaje, con colores saturados y pinceladas sueltas. En su tela, que cubría las paredes del pabellón, se van sucediendo distintos paisajes amalgamados en uno solo; representa el campo, el litoral con el delta y los barcos; el puerto con los silos; la pampa húmeda y zonas más boscosas [Figura 1]. Están ausentes de su pintura la Patagonia, así como la cordillera. Dentro del paisaje se ven algunos hombres y mujeres junto con los animales que pueblan el suelo.

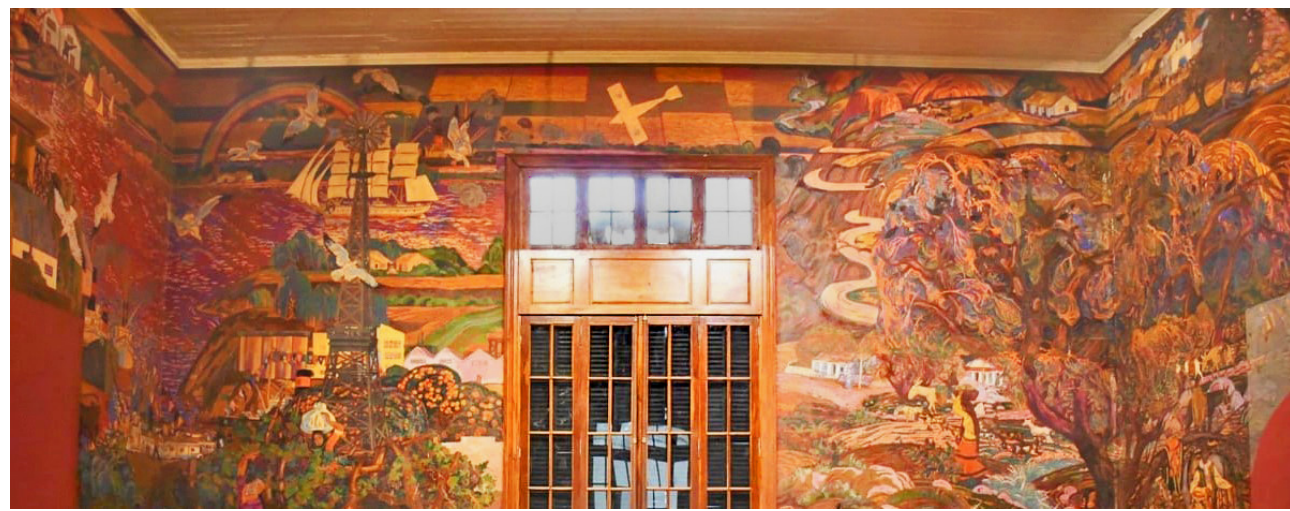

Figura 1. Uno de los cuatro muros de la tela para la «Exposición Iberoamericana de Sevilla» (1928), Alfredo Guido

Guido busca en las figuras un tono de piel que dé cuenta del mestizaje, de esa síntesis euríndica. Se observan, también, escenas de los trabajos que se realizan en ese paisaje: un rancho, una pequeña iglesia con los muros blanqueados que recuerda a las pequeñas iglesias del noroeste argentino, y una fiesta donde se ven instrumentos típicos del folclore [Figura 2].

5 Para un análisis pormenorizado de la propuesta arquitectónica de Martín Noel, véase El arquitecto Martín Noel. Su tiempo y su obra (1995), de Ramón Gutiérrez, Margarita Gutman y Víctor Pérez Escolano.

6 La relación entre Alfredo Guido y Enrique Larreta reconocía momentos anteriores, como el pedido de Larreta de que realizara el grabado de la portada de Zogoibi, libro que trata sobre la vida en las estancias a comienzos del siglo Xx publicado en 1926. 
Guido había realizado un viaje a Jujuy y, ya en sus obras más tempranas y en su participación en la revista de El círculo, se puede observar un interés por representar paisajes del noroeste argentino y del altiplano boliviano, como ha demostrado Adriana Armando (2004, 2014).

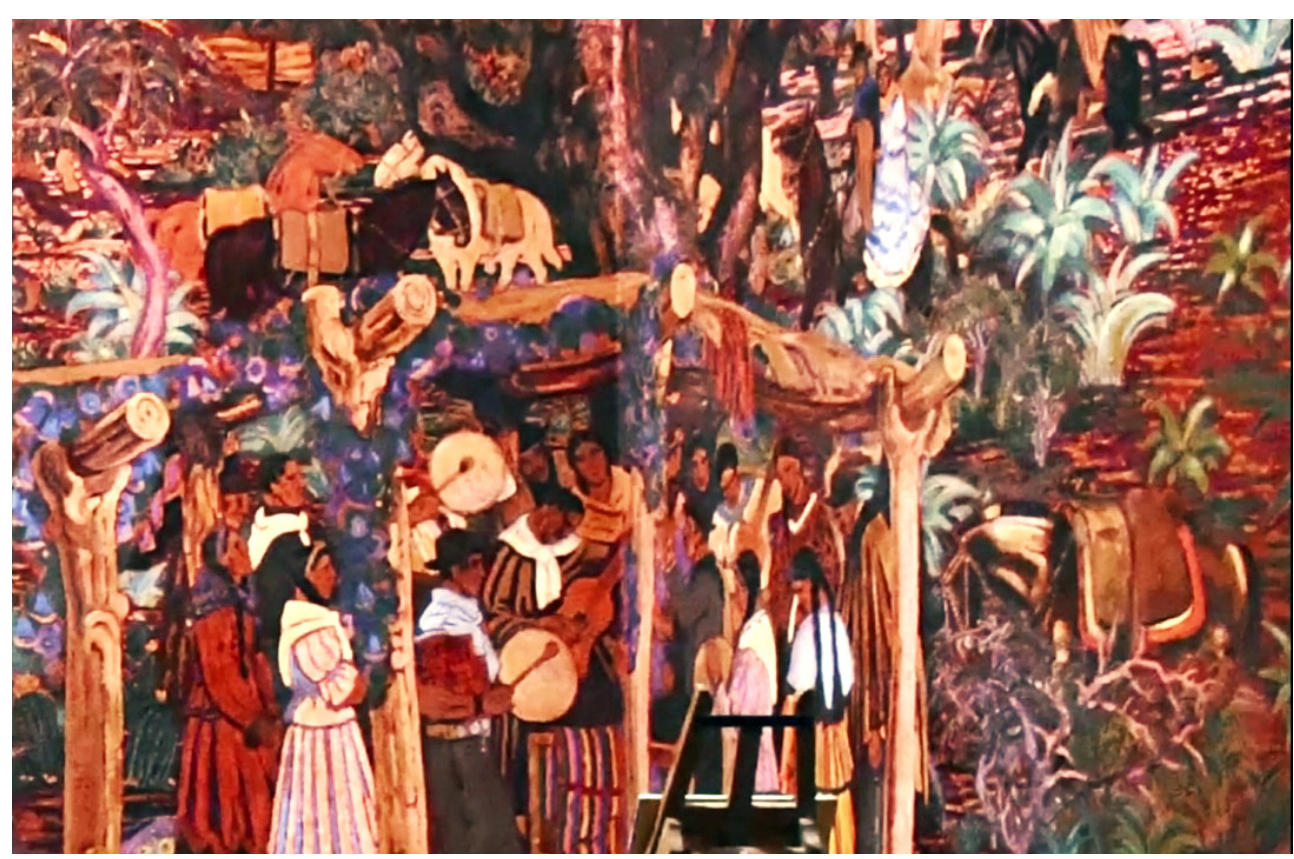

Figura 2. Detalle del mural para la «Exposición Iberoamericana de Sevilla» (1928), Alfredo Guido

\section{LA PRESENCIA DEL ARTE MURAL EN LA FERIA DE PARÍS}

El entramado de intercambios en relación con la pintura mural sobre ideas, técnicas y motivos que se dio en las exposiciones, en especial, en la «Exposición Internacional de París. De las Artes y las Técnicas en la vida moderna», en 1937, resulta notable. En dicha oportunidad se exhibieron el Guernica, de Pablo Picasso, en el Pabellón español; bocetos de José Clemente Orozco, David Alfaro Siqueiros y Diego Rivera, en el Pabellón mexicano; bocetos de Thomas Hart Benton, en el estadounidense; un mosaico de Mario Sironi, Italia corporativa, en el italiano; y el panel de Spilimbergo Las Industrias Artesanales, en el Pabellón argentino. Esta exposición se enmarcó en el clima de preguerra y estuvo teñida por los sucesos de la guerra civil española y de la violencia denunciada por Picasso en su obra. Más allá de si los artistas viajaron y tuvieron la oportunidad de observar esas obras, se debe señalar el hecho de que todas estas obras murales, producto de distintas situaciones políticas y económicas, producidas por artistas de distinto signo político, compartieron el espacio de la exposición. Sin duda circularon más tarde catálogos, fotos y críticas en los diarios que se hicieron eco de la trascendencia de aquello que se expuso. Por otro lado, también nos habla de hasta qué punto los artistas locales se encontraban realizando producciones similares a lo que se consideraba moderno en ese momento.

El Pabellón argentino estaba construido en estilo racionalista y con marcadas líneas verticales. En su interior contaba con una sección para la industria, otra para productos agrícolas y, quizás lo más notable, la barca-restaurante Pampa sobre el Sena, donde se podían degustar platos típicos argentinos.

El panel que pintó Spilimbergo para decorar uno de los muros era Las Industrias Artesanales (Wechsler, 1999). Con un tratamiento monumental y geométrico de las figuras y volúmenes, representó el paisaje norteño de los cerros que daba marco a un grupo de seis hombres y mujeres del altiplano. Unos tejiendo con telares tradicionales, mientras en el centro de la obra un hombre muestra al espectador una manta, cuya guarda central copia rítmicamente 
el paisaje al tiempo que representa un patrón con cóndores cuyos picos se enlazan con la cola del siguiente. Otros motivos andinos que aparecen son el tukapu y el caxane, que se pueden encontrar en dibujos y diseños incas. ${ }^{7}$ Es probable que el artista haya tomado una serie de símbolos andinos y creado su propio diseño para representar la cosmovisión andina [Figura 3]. Este tipo de aproximación al paisaje y sus pobladores presentaba una suerte de esencia americanista, que se pretendía más pura y no contaminada por el cosmopolitismo de las ciudades (Amigo, 2014).

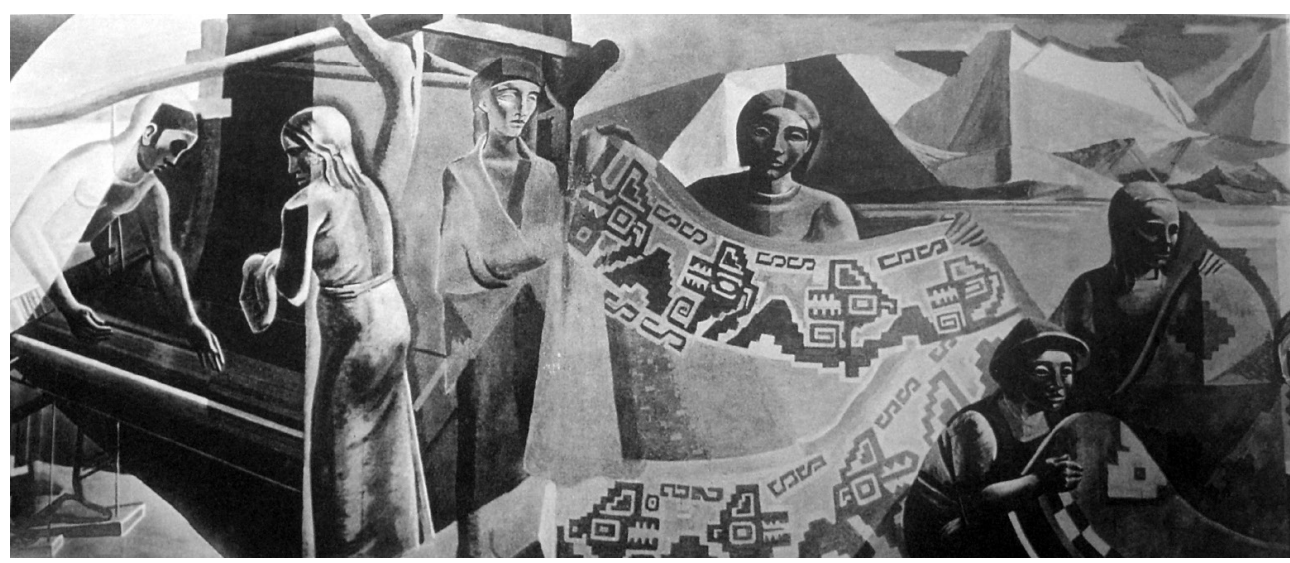

Figura 3. Las Industrias Artesanales, «Exposición Internacional de París» (1937), Lino Enea Spilimbergo. Crédito: Spilimbergo (1999), de Guillermo Whitelow, Fermín Fèvre y Diana Wechsler

\section{POSTALES DE LA PRODUCCIÓN}

Tan solo dos años más tarde se realizó el envío para la Feria Mundial. El Mundo del Mañana, en Nueva York (1939). ${ }^{8}$ Por encargo de la Comisión Nacional de la Participación Argentina en las exposiciones internacionales, los artistas Berni, Spilimbergo, Montero, Raúl Mazza y Jarry trabajaron en el predio de la Sociedad Rural donde en cuarenta días pintaron las grandes piezas de catorce metros de largo por ocho de altura. Según el cronista de la revista El Hogar, trabajaban "sobre las dos enormes telas desplegadas y fijadas en el piso del amplísimo hall que la Sociedad Rural tiene destinado para Museo Agrícola, frente a la plaza Italia, en la calle Santa Fe" (Marty, 1939, s. p.). Tenían una escalera movible de veinte metros que utilizaban para observar desde la altura el avance de la pintura de las telas tendidas en el suelo. ${ }^{9}$

Berni y Spilimbergo tomaron un tema diametralmente opuesto al que había tratado este último para la exposición en París. En Agricultura y Ganadería se destacaba una visión idealizada de los productos del comercio agroexportador, así como la figura del gaucho como artífice de los trabajos rurales. En este nuevo intento por lograr una imagen que representara la nación se dejaba de lado el paisaje andino y sus pobladores para dar paso a la pampa húmeda y el gaucho: "Han tratado de destacar los atributos esenciales de la prosperidad material de nuestro suelo: la agricultura y la ganadería» (Marty, 1939, s. p.). Asimismo, el periódico La Capital, de Rosario, resaltaba el carácter monumental de la obra:

Trátase de una pintura al temple que mide ocho metros de ancho por catorce de largo y que ostenta todas las características del bajo relieve esculpido en piedra [...]. La composición simbólica como decimos, representa la prosperidad de la agricultura y ganadería argentinas. En el centro, dos robustas y mansas manos se estrechan en medio de un resplandor áureo, originado por el fulgor de

7 Agradezco los comentarios de la antropóloga y especialista en textiles andinos Cristina Bubba para la lectura de esta obra.

8 Ese año también se celebró la «Exposición Internacional de Golden Gate», donde también participó la Argentina con un pabellón. En su interior se encontraba un mural de Ernesto Scotti.

9 Se desconoce el paradero de estas obras, se supone fueron destruidas. No se han encontrado imágenes del emplazamiento de la obra Industria y Comercio. 
maravillosas espigas de trigo. Son manos laboriosas, pacíficas, benéficas, que nada piden y todo dan. Las mismas que se estrechan en el escudo nacional para significar la paz y la armonía de los pueblos y la tranquilidad del ciudadano (Una simbólica concepción decorativa, 1939, p. 15).

Ezequiel Adamovsky (2019), en sus trabajos sobre la figura del gaucho como emblema de la argentinidad, señala que es un símbolo políticamente inestable e incontrolable del que, a partir de la década de 1930, la derecha argentina se apropia y, de esta manera, domestica su representación. Ya no se trata del Martín Fierro díscolo, del gaucho fugitivo; es, en cambio, el poblador de la pampa húmeda y el trabajador rural, tal como lo vemos plasmado en esta obra [Figura 4].

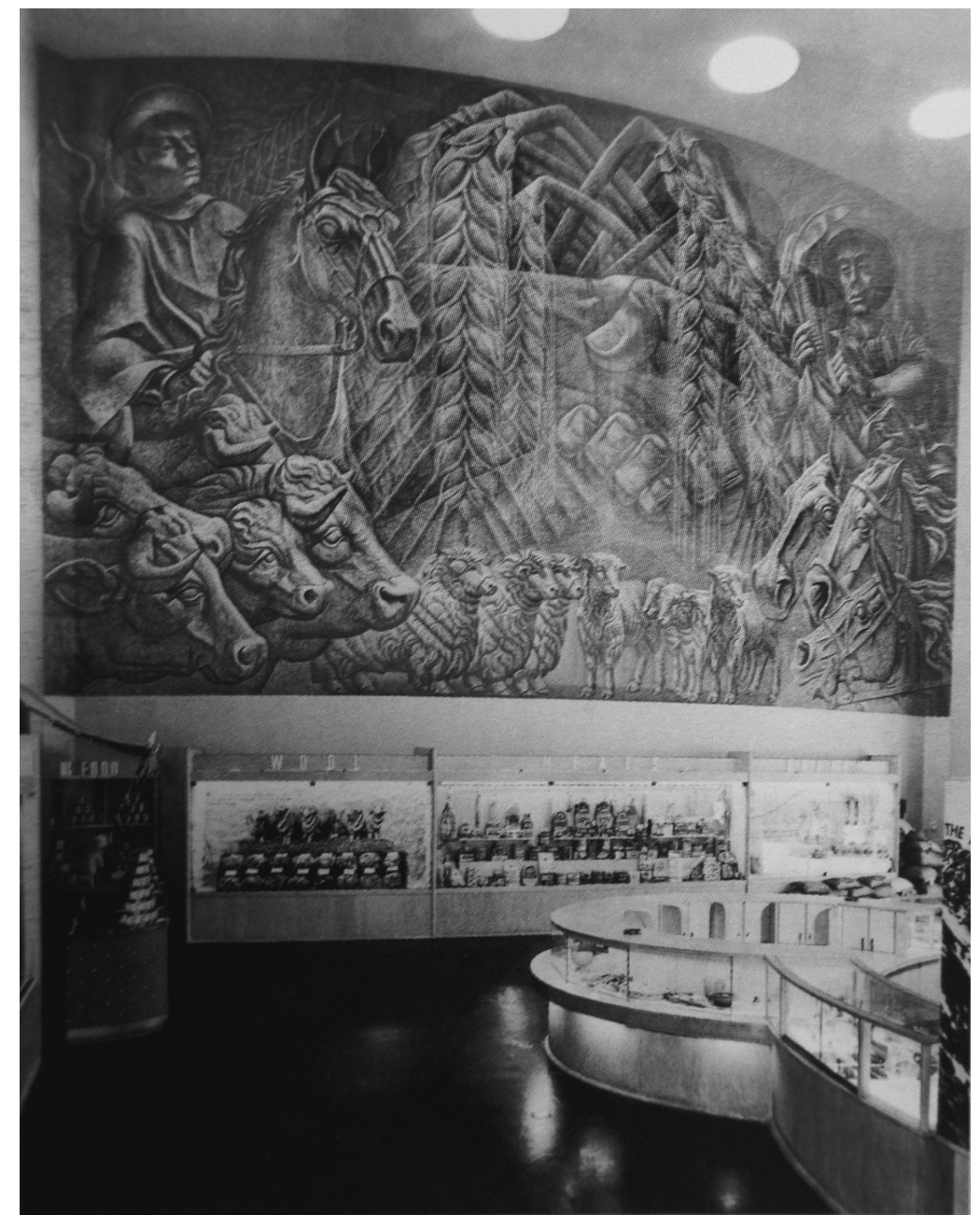

Figura 4. Agricultura y Ganadería, Feria Mundial de Nueva York (1939), Antonio Berni y Lino E. Spilimbergo. Crédito: «Dos gigantescos cuadros de artistas argentinos lucirá el gran hall central de la Exposición Internacional de Nueva York» (1939), de J. A. Marty

El segundo mural que decoró el pabellón es Industria y comercio, de Montero, Jarry y Mazza [Figura 5]. Con una estética monumentalista se observa una multitud de hombres anónimos (y algunas mujeres) entregados al trabajo, utilizando herramientas, moviendo palancas y manejando maquinarias. Sus músculos nos hablan de un trabajo esforzado, cargan canastos, mueven engranajes y otros elementos que remiten a la industria. Domina la escena una figura femenina alegórica que representa la industria. En un último plano, se adivinan unas torres petroleras, los humos de las fábricas, los silos y barcos transatlánticos. 


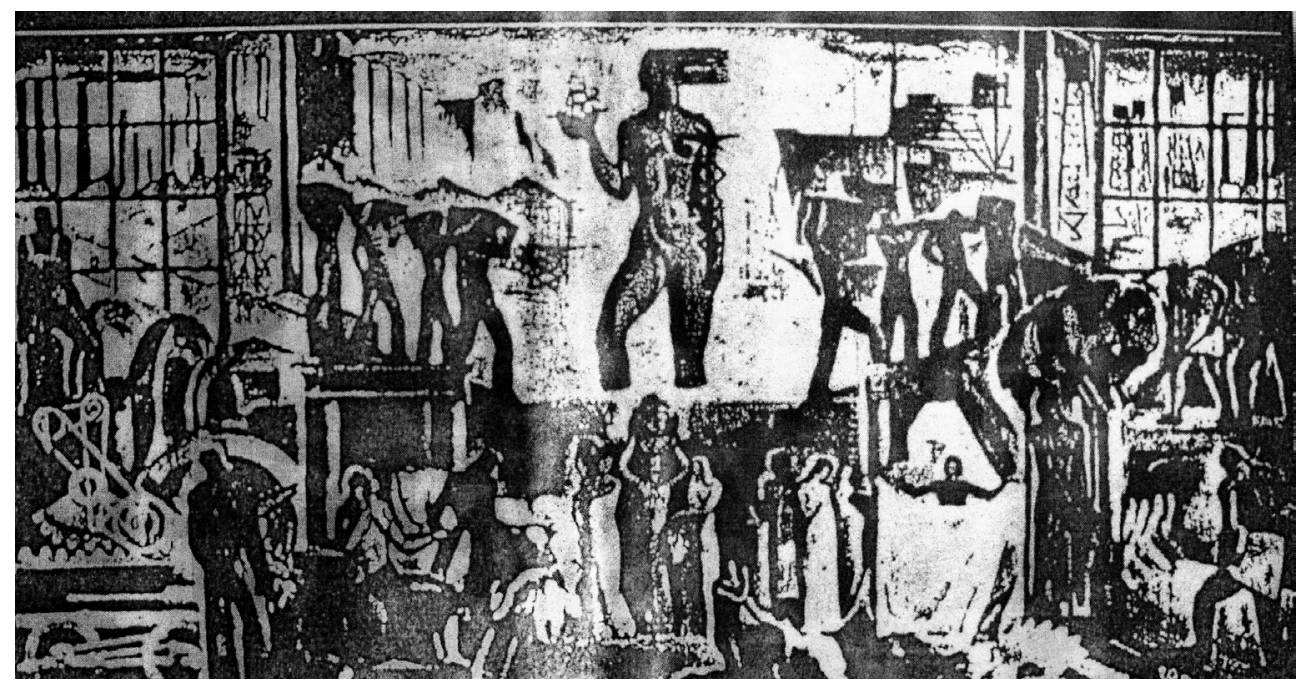

Figura 5. Industria y Comercio, Feria Mundial de Nueva York (1939), Adolfo Montero y Gastón Jarry. Feria Mundial de Nueva York Crédito: «Dos gigantescos cuadros de artistas argentinos lucirá el gran hall central de la Exposición Internacional de Nueva York» (1939), de J. A. Marty

En estos dos grandes paneles aparece una figuración mucho más ligada a la producción, por un lado, a la agricultura y a la ganadería, a la riqueza del país a través de su exportación. Y por el otro, la representación de la industria en un entorno urbano, del trabajo asociado a las herramientas y las máquinas, en consonancia con el empuje que había recibido la industria con el proceso de sustitución de importaciones.

Finalmente, las exposiciones universales durante el período de entreguerras caen dentro de las paradojas y la inestabilidad de la época, dado que apenas terminada la exposición de Nueva York estalló la Segunda Guerra Mundial. El afán por demostrar que se trataba de naciones modernas y civilizadas perdió sentido dando paso a la lógica de la guerra.

\section{CONCLUSIONES}

Durante el período de entreguerras el Estado argentino participó con pabellones nacionales en varias exposiciones internacionales en las cuales se exhibía a los ojos del mundo una imagen de nación pujante, tanto desde lo económico como desde lo cultural. Los murales de los pabellones proyectaban imágenes que expresaban un ideal de lo que se consideraba propio. Estos tenían la función de otorgar a los productos exhibidos una dimensión simbólicocultural. Al finalizar las exhibiciones los paneles se desechaban; por esto solo pudimos acceder a ellos a partir de fotografías y de otros documentos, como cartas y notas periodísticas. Este trabajo es un intento por echar luz sobre obras que tuvieron mucha importancia en su momento de producción, pero que, sin embargo, permanecen olvidadas. El análisis de los murales que cubren los muros de los pabellones permite un mayor conocimiento con relación a qué nociones de la Argentina se exhibieron. Los artistas convocados para realizar los murales buscaron sintetizar una imagen emblemática de la identidad argentina que fue cambiando a lo largo del tiempo y que en el lapso de pocos años presentó ambivalencias respecto de aquello que se representó como lo nacional.

Por un lado, se observa una tensión en torno a realizar una representación con rasgos indígenas, criollos o europeos; por el otro, se sostiene la armonía y el progreso a partir del modelo agrícola ganadero exaltando el campo y los trabajos que allí se realizan. Así, el ideal de riqueza asociado a los productos primarios estaba presente, ya fuera a partir de los productos exhibidos o, como en el caso de la exposición de 1937, con el restaurante Pampa. En los distintos encargos de paneles se van ensayando modos alternativos de presentar postales que den cuenta desde lo visual de aquello que define lo nacional tanto a través de los paisajes 
como de la gente. A lo largo del período se construye capa sobre capa un imaginario de lo argentino. Hacia el final del período se condensa una imagen de la Argentina asociada a la agricultura, a la ganadería y a la industria.

\section{REFERENCIAS}

Amigo, R. (2014). La hora americana 1910-1950. El americanismo del indianismo al indigenismo. En R. Amigo y A. Petrina (Cur.), La hora americana 1910-1950. Ciudad Autónoma de Buenos Aires, Argentina: Museo Nacional de Bellas Artes.

Adamovsky, E. (2019). El gaucho indómito: de Martín Fierro a Perón, el emblema imposible de una nación desagarrada. Ciudad Autónoma de Buenos Aires, Argentina: Siglo Veintiuno.

Armando, A. (2004). Entre telas: las mujeres en las obras de Alfredo Guido y Antonio Berni. Separata. Centro de Investigaciones del Arte argentino y latinoamericano, 4(748), 37-55.

Armando, A. (2014). Alfredo Guido y el americanismo en los años veinte. En R. Amigo y A. Petrina (Cur.), La hora americana 1910-1950 (pp. 189-203). Ciudad Autónoma de Buenos Aires, Argentina: Museo Nacional de Bellas Artes.

Belej, C. (2011). Entre el panamericanismo y el nacionalismo. Alfredo Guido y su mural para el Automóvil Club Argentino. Papeles de Trabajo. Revista del Instituto de Altos Estudios Sociales-Universidad Nacional de San Martín, 4(7), 93-113. Recuperado de http:/l revistasacademicas.unsam.edu.ar/index.php/papdetrab/issue/view/16

Belej, C. (2014). "Una exposición permanente». Políticas de la imagen en los edificios públicos a través de sus murales en la década de 1930. Travesía. Revista de historia económica y social, (16), 29-50. Recuperado de http://www.travesia-unt.org.ar/pdf/numero16/ ceciliabelej.pdf

Benjamin, W. (2004). El libro de los pasajes. Madrid, España: Akal.

Christophersen, A. (1923). Pabellón Argentino en la Exposición Internacional de Río de Janeiro de 1922. Revista de Arquitectura, (34), 65-75.

Guido, A. (25 de enero de 1927). Rosario 1927 [Correspondencia de Enrique Larreta]. Archivo Museo de Arte Español Enrique Larreta, Ciudad Autónoma de Buenos Aires, Argentina.

Gutiérrez, R. (2014). Persistencia y cambio en la arquitectura simbólica. Los pabellones argentinos en las exposiciones 1915-1940. Temas de la Academia: cambios y persistencias en tiempos de transición, 12(12), 57-72.

Gutman, M. (1995). El Pabellón Argentino en la Exposición Iberoamericana de Sevilla. En R. Gutiérrez, M. Gutman y V. Pérez Escolano (Eds.), El arquitecto Martín Noel. Su tiempo y su obra (pp. 147-159). Sevilla, España: Junta de Andalucía, Consejería de Cultura.

Holly, M. A. y Moxey, K. (Eds.). (2002). Art History, Aesthetics, Visual Studies [Historia del arte, Estética, Estudios visuales]. Massachusetts, Estados Unidos: Sterling \& Francine Clark Art Institute.

Marty, J. A. (marzo de 1939). Dos gigantescos cuadros de artistas argentinos lucirá el gran hall central de la Exposición Internacional de Nueva York. El Hogar.

Schrenk, L. (1999). From Historic Village to Modern Pavilion: The Evolution of Foreign Architectural Representation at International Expositions in the 1930s [De las aldeas históricas a los pabellones modernos: evolución de la representación arquitectónica extranjera en las Exposiciones Internaciones en los años treinta]. National Identities, 1(3), 287-311. Recuperado de: https://www.tandfonline.com/doi/ citedby/10.1080/14608944.1999.9728116?scroll=top\&needAccess=true

Una simbólica concepción decorativa será presentada en la próxima Exposición Internacional de Nueva York. (14 de marzo de 1939). La Capital, 15.

Wechsler, D. (1999). 1937: Argentina en la Exposición Internacional de París. En G. Whitelow, F. Fèvre y D. Wechsler (Eds.). Spilimbergo. Ciudad Autónoma de Buenos Aires, Argentina: Fondo Nacional de las Artes. 